\title{
Autism, an area that needs public attention and investment
}

\author{
Jane Y. WU ${ }^{1,2}$ \\ ${ }^{1}$ Department of Neurology, Center for Genetic Medicine, Lurie Cancer Center, Northwestern University Feinberg School of Medicine, \\ Chicago, IL 60611 USA; \\ ${ }^{2}$ State Key Laboratory of Brain and Cognitive Science, Institute of Biophysics, Chinese Academy of Sciences, Beijing 100080, China
}

Citation: Wu JY. Autism, an area that needs public attention and investment. Sci China Life Sci, 2015, 58: 931-932, doi: 10.1007/s11427-015-4940-2

I would like to dedicate this special issue to children and adults who are affected by autism or related developmental disorders, as well as to their families and friends. I am indebted to the clinicians and care providers who have made tremendous effort in supporting these patients. They have inspired me to invest a significant amount of my energy to adventure into this area. I greatly appreciate all the contributing authors around the world whose hard work made this special issue possible.

I am grateful to all my friends and collaborators who have kindly supported autism research in China by giving lectures, visiting hospitals, providing suggestions and contributing in other ways. I would like to thank my colleagues Jianghong Liu and Li Zhu as well as other members of $\mathrm{Wu}$ laboratory for assisting me in various aspects of putting together this special issue. In addition to the authors who directly contributed to this special issue, I would like to acknowledge Drs. Brett S. Abrahams, David Amaral, Margaret Bauman, Arthur Beaudet, Catalina Betancur, Randy Blakely, Joseph D. Buxbaum, Michael Caterina, Edwin Cook, Geraldine Dawson, Fan Jiang, Daniel Geschwind, Michael Greenberg, Alice Kau, Young Shin Kim, Catherine Lam, Bennett Leventhal, Pat Levitt, Charlene Liao, Catherine Lord, Cindy Lower, Liqun Luo, Declan Murphy, Charles A. Nelson, Eric Nestler, Thomas Owley, Luis Parada, Craig Powell, Leonard Rappaport, Catherine Rice, Xiaoxi Qiao, Louis F Reichardt, Andy Shih, Lisa Stanford, Thomas Südhof, Matthew State, Christopher Walsh, Shinya

email: jane-wu@northwestern.edu
Yamanaka, Larry J. Young and Huda Zoghbi, for their kind support.

Autism, also known as autism spectrum disorders (ASD), is a group of prevalent neurodevelopmental disorders. ASD presents as a spectrum of syndromes characterized by impairments in social interactions, difficulties in verbal or non-verbal communication, as well as restricted and stereotyped patterns of interests and behavior.

Recent studies from the U.S. and other countries suggest that the prevalence of ASD may be as high as approximately 1 in 100 among boys. As compared with developed countries, China has lagged behind in social awareness about ASD and related research development. Autism Consortium China (ACC), a collaborative platform for autism research and clinical studies, was established at the end of 2009 in order to raise the public awareness, increase support for autism research and promote collaborations between China and the international community. Organized and co-chaired by Drs. Liping Wei, Bailin Wu, Xin Yu and myself, the $369^{\text {th }}$ session of the Xiangshan Science Conferences was convened in 2010 in Beijing, China with the theme of "Status Quo and Frontiers of ASD Studies". Over the past few years, the ACC has organized a number of research forums and public events to promote autism research and patient support in China. However, government investment on ASD research and for patient care in China is still far from sufficient. A major goal of this special issue is to rally stronger support for ASD, a major health issue in child development that has been largely overlooked and urgently deserves public attention. 


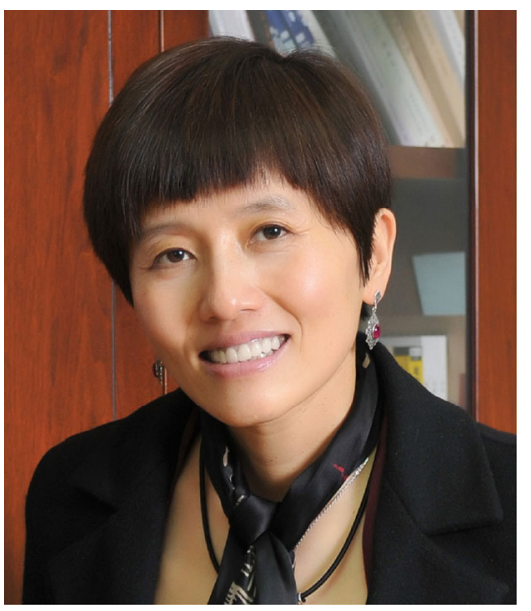

Biographical Sketch

Jane Y. Wu, M.D., Ph.D., is the Charles Louis Mix Professor of Neurology, Northwestern University Feinberg School of Medicine. She received her doctoral degree in cancer biology from Stanford University. Her research interests include post-transcriptional gene regulation and its involvement in pathogenesis of age-related diseases, especially neurodegeneration and tumor pathogenesis. She received the Novo Nordisk Great Wall Professorship Award in 2009. She is an elected member of American Society of Clinical Investigation, Association of American Physicians as well as an AAAS Fellow. She was also selected in the Thousand Talents Program of China. She published more than 150 research articles in international journals, including Cell, Nature, Science, Nature Neuroscience, Nature Structural \& Molecular Biology, and Journal of Clinical Investigation. She has served on editorial boards for Journal of Biological Chemistry, Gene Regulation \& Systems Biology, Clinical \& Translational Science, Protein \& Cell, and Science China Life Sciences.

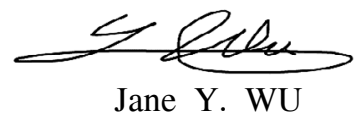

October, 2015

Open Access This article is distributed under the terms of the Creative Commons Attribution License which permits any use, distribution, and reproduction in any medium, provided the original author(s) and source are credited. 